milder course in primary SS, with no vascular complications and needing pharmacological treatment in only $40 \%$ of patients. The clinical course of RP seems to be milder in patients with primary SS than in other systemic autoimmune diseases such as systemic sclerosis.

\section{FRI0214 INCIDENCE OF PANCREATIC AUTOANTIBODIES IN PRIMARY SJÖGREN SYNDROME}

${ }^{1} \mathrm{~K}$ Aksu, ${ }^{1} \mathrm{G}$ Altan Oder, ${ }^{1} \mathrm{Y}$ Kabasakal, ${ }^{1} \mathrm{G}$ Keser, ${ }^{1} \mathrm{~V}$ Inal, ${ }^{1} \mathrm{~A}$ Isik, ${ }^{2} \mathrm{~S}$ Cetinkalp, ${ }^{1} \mathrm{E}$ Doganavsargil. 'Rheumatology; ${ }^{2}$ Endocrinology, Ege University, Faculty of Medicine, Izmir, Turkey

\subsection{6/annrheumdis-2001.307}

Background Primary Sjögren $(\mathrm{Sj} S)$ syndrome is one of the prototypes of autoimmune diseases.

Objectives We aimed to work out the incidence of pancreatic autoantibodies in this disease.

Methods Seventy-six patients (F/M: 71/5, mean age: $49 \pm 13$ years) diagnosed as primary SjS syndrome according to the San Diego criteria between February 1997 and December 2000, have been included in the study. Twenty two, age matched $(52 \pm 10$ years) female patients with secondary $\mathrm{SjS}$ due to rheumatoid arthritis were defined as the control group. Healthy control group included 22 age matched (F/M: 21/1) patients. Immunosuppressive drug usage, liver or renal failure were within the exclusion criteria. Serum samples for anti-insulin (AIA), islet (ICA) and anti-insulin receptor (IRA) antibodies were obtained from all patients after an $18 \mathrm{~h}$ fasting.

Results The incidence of anti-insulin antibody was found as $17 \%$, while it was $7 \%$ and $\% 17$ for islet antibodies and antireceptor antibodies, respectively (Table 1 ). These values were not statistically significant when compared with secondary SjS and healthy control groups $(\mathrm{p}>0.05)$.

Abstract FRI0214 Table 1 Incidence of pancreatic autoantibodies

\begin{tabular}{lllll}
\hline & Primary SjS\% & Secondary SjS\% & Healthy control\% & p \\
\hline AIA & $17(n=13)$ & $22(n=5)$ & $18(n=4)$ & $p>0.05$ \\
IRA & $17(n=13)$ & $18(n=4)$ & $18(n=4)$ & $p>0.05$ \\
ICA & $7(n=5)$ & $13(n=3)$ & $13(n=3)$ & $p>0.05$ \\
\hline
\end{tabular}

Conclusion Incidence of pancreatic auto-antibodies in primary SjS with observed hyperactivity of B cells, was not found statistically different when compared with patient and healthy control groups.

\section{FRI0215 SJÖGREN'S SYNDROME MANIFESTATIONS IN PRIMARY BILIARY CIRRHOSIS}

C Geli, J Enriquez, C Diaz, JM Llobet, M Moreno, C Diaz-Torne, A Rodriguez de la Serna, G Vazquez. Rheumatology Unit, Hosptital de La Santa Creu I Sant Pau, Barcelona, Spain

10.1136/annrheumdis-2001.308

\section{Background}

Objectives Study the Sjögren's Syndrome (SS) manifestations in a sample of patients with Primary Biliary Cirrhosis.

Methods From October 1999 to May 200081 patients from the hepatology outpatient department were studied. We used the european criteria for the diagnostic of SS. Extraglandular clinical manifestations, analitical and inmunological study was evaluated using the unity protocol.

Results $90 \%$ were women. The mean age was $61 \pm 11$ y. Clinical evolution was of 6 years. Ocular dryness was present in 60 $(74 \%)$ and oral dryness in 60(76\%). Schirmer and/or bengal's rose were positive in $21(26 \%)$. The most common extraglandular manifestations were: Fibromialgy in 42(51\%), Raynaud's phenomenom in $21(26 \%)$, CREST's syndrome in $13(16 \%)$, thyropathy in $21(26 \%)$, antythyroidal antibodies were positive in $19(24 \%)$ (Ten of them had hipothyroidism and two of them goitres), arthritis in 7(9\%)(Two of them were erosive), inflammatory osteoarthritis in 5(6\%), vasculitis in $3(4 \%)$, ANA $>80$ in 47 $(58 \%)$, Rheumatoid factor in $27(33 \%)$, SS-A/Ro antibodies in 14 $(17 \%)$ and SS-B/La in $8(10 \%) .9$ CREST's patients were positive for anticentromere antibodies. $41(50 \%)$ had 4 or more SS European criteria. A minor salival gland biopsy was realised in 53 patients. 39 of them were positive (73\%). 41 of the biosed patients had 3 or more criteria. 31 of this 41 patients has a positive biopsy (75\%). The other 12 patients had 2 or less criteria, just 5 of them had a positive biopsy (41\%).

Conclusion There is a high prevalence of SS (50\%) in patients with CBP. Keratoconjuctivitis sicca's prevalence is $66 \%$. Subjective involvement of oral and ocular dryness are $74 \%$ and $76 \%$ respectively. Fibromialgy is the rheumatological clinic more frequent, appearing in more than $50 \%$ of the patients.

\section{FRI0216 ANTIBODIES TO RECOMBINANT 60-KD RO, 52-KD RO AND 48-KD LA PROTEINS IN PRIMARY SJÖGREN'S SYNDROME. USEFULNESS OF COMBINATION OF ANALYTICAL METHODS FOR DETECTING ANTI-RO AND ANTI LA ANTIBODIES}

${ }^{1} S$ Aguilera, ${ }^{2} \mathrm{D}$ Castillo, ${ }^{3} \mathrm{~J}$ González. ${ }^{1}$ Rheumatology; ${ }^{2}$ Inmunology; ${ }^{3}$ Department of Cellular and Molecular Biology, University of Chile, Santiago, Chile

10.1136/annrheumdis-2001.309

\section{Background}

Objectives To determine the reactivity and specificity of sera from primary Sjögren's syndrome (SS) patients to recombinant $60-\mathrm{Kd}$ Ro, 52-Kd Ro and 48-Kd La proteins, and to correlate the results with clinical and laboratory findings.

Methods Sera from 46 patients with primary SS diagnosed according to modified 1997 European criteria, were classified in 2 groups based on the presence of anti- Ro and anti-La detected by commercial enzyme linked immunobsorbent assay (ELISA). Group A ( $\mathrm{n}=32)$ had anti-Ro positive sera, and group B $(\mathrm{n}=$ 14) had anti-Ro and anti-La negative sera, but positive antinuclear antibodies and/or rheumatoid factors. Autoantibody reactivity and specificity to recombinant $60-\mathrm{Kd}$ Ro, $52-\mathrm{Kd}$ Ro and 48Kd La were analysed by ELISA and Western blot.

Results Forty-two out of 46 primary SS sera (91.30\%), had reactivity to either natural or recombinant antigens or both. Anti-60Kd Ro was found in $27(58.69 \%)$ of all sera, of these, 22 $(68.75 \%)$ sera were of group A, and 5 sera (35.71\%) of group B. Anti-52-Kd Ro was highly prevalent since 38 out of 46 sera (62.60\%) were positive. Among group A, 31 out of 32 (96.87\%) sera were positive for 52-Kd Ro, and 7 out of $14(50 \%)$ in group B. Anti-recombinant $48-\mathrm{Kd} \mathrm{La}$ was also highly prevalent, $38(82.60 \%)$ of all sera were positive. In group A, $31(96.87 \%)$ of sera were positive, while $5(35.71 \%)$ of sera of group B, were positive. Ten (71.42\%) of 14 patients of group B had antibodies for at least 1 of 3 recombinant antigens: $52-\mathrm{Kd}$ Ro, 60-Kd Ro or 